\title{
Quality of life of elderly people who care for other elderly people with neurological diseases
}

\author{
Julimar Fernandes de Oliveira' \\ Lais Lopes Delfino' \\ Samila Sathler Taveres Batistonil \\ Anita Liberalesso Neri' \\ Meire Cachionil
}

\section{Abstract}

Objective: to investigate the relationships between the perceived quality of life of elderly people who care for other elderly people with neurological diseases (dementia and strokes) and the gender, age and caregiver burden, diagnosis, functional dependence, and cognitive status of the care recipient. Method: 75 caregivers aged over 60 years were interviewed using the Quality of Life Scale (CASP-19) and Zarit Burden Interview. The levels of physical vulnerability of the elderly were identified through the Lawton and Brody questionnaires and the Katz scale and the cognitive assessment of elderly care recipients was assessed with the Clinical Dementia Rating. The data were analyzed by chi-squared test (for comparison of categorical variables), Mann-Whitney and KruskalWallis $U$ tests (for comparison of continuous variables). To study the associations between variables, univariate logistic regression analysis was performed, followed by multivariate logistic regression analysis. Results: the age, gender of the caregiver, type of neurological condition, and physical and cognitive functioning of the care recipient did not statistically influence the quality of life of the caregiver. Elderly caregivers with higher levels of burden $(\geq 29)$ were 11.4 times more likely to have a worse quality of life score (CI: $3.16-36.77 ; p<0.001)$. Conclusion: the quality of life of the elderly caregiver is negatively influenced by the burden involved in caring for another elderly person. Identifying the negative emotional aspects of caregivers that negatively affect their quality of life should be considered a target for intervention by health teams.

\footnotetext{
Universidade Estadual de Campinas, Faculdade de Ciências Médicas, Programa de Pós-Graduação em Gerontologia. Campinas, São Paulo, Brasil.

Keywords: Quality of Life. Caregivers. Elderly. 


\section{INTRODUCTION}

One characteristic of the epidemiological changes that accompany population aging is the growth of the proportion of elderly persons with chronicdegenerative diseases. Among these diseases are strokes and dementias of various etiologies ${ }^{1}$. Diseases that generate significant physical and psychological impairments are also associated with a progressive loss of independence and autonomy, behavioral changes and the need for care of an instrumental, material, social and emotional nature ${ }^{2}$.

The levels of physical and cognitive dependence associated with strokes and dementias range from difficulties in mobility to more complex levels of physical disability, which involve dependence in the performance of activities related to personal care ${ }^{3}$. These situations have a direct impact on the well-being of family caregivers, who generally perform their role without help or appropriate guidance. Caregivers often become involved in conflicts, anxiety, depression, stress, fears and experience a sense of burden that can have an impact on quality of life ${ }^{4}$.

The World Health Organization ${ }^{5}$ (WHO) defines quality of life as "the individual's perception of their position in life in the context of the culture and value systems in which they live and in relation to their goals, expectations, standards and concerns". There are several factors that are related to the perceptions of quality of life of elderly caregivers, including the quality of personal relationships, sociodemographic characteristics such as age and gender, the degree of burden and the abilities to deal with dependent elderly recipients of care ${ }^{6}$.

Population aging has repercussions on two important phenomena. Firstly, there are more people with neurological diseases such as dementias and/or strokes, who exhibit several physical and cognitive functional losses, and secondly, there are more elderly caregivers. The growing number of elderly people can lead to these individuals being burdened by a condition of dual vulnerability due to the burden of care and the aging process. Such situations may influence the psychological, physical and social health of caregivers, affecting their perception of quality of life. The variability of factors that influence quality of life and its subjectivity impose reflections on aging and make it essential understand the factors that contribute to the well-being of caregivers in each age group ${ }^{7,8}$.

Those involved in care are constantly exposed to depressive feelings and burden, which increases with the greater dependence of the care recipient and negatively influence the health of caregivers ${ }^{9-11}$. Positive and negative feelings, psychological conflicts, grief, fear and insecurity are common throughout the caring experience ${ }^{6}$. Caldeira et al. ${ }^{12}$ state that this burden and the physical and cognitive frailty of the caregiver are strongly associated with low caregiver quality of life scores, and that this influences negative perceptions about satisfaction with life.

The psychological resources of caregivers to deal with difficult situations may be inadequate to meet their life needs and the needs of the elderly care recipient, resulting in negative personal perceptions about their quality of life. Engaging in the care of an elderly person often results in the caregiver setting aside their life in favor of assuming responsibility for the life of another, restricting their ability to care for their own health and resulting in negative effects on their quality of life ${ }^{13,14}$.

The present study aimed to investigate the relationships between the perceptions of quality of life of elderly caregivers of elderly people with neurological diseases (dementia and strokes) and gender, age and caregiver burden, as well as the diagnosis, functional dependence and cognitive status of the care recipient.

\section{METHODS}

The present study integrated the database of the study entitled "The psychological well-being of elderly people who take care of other elderly people in a family context", which had a convenience sample of 148 participants indicated by professionals linked to public and private services aimed at the elderly, such as elderly care clinics, home care and medical services.

These caregivers met the following inclusion criteria: age 60 or older, had been a caregiver for at least six months, and agree to participate in the survey. Caregivers who scored below the cutoff point of the Cognitive Abilities Screening Instrument - 
Short Form (CASI-S) were excluded ${ }^{15}$. These cutoff points were 23 for elderly persons aged 60 to 69 years, and 20 for those aged 70 or older.

The Proc Power procedure of the SAS program (Statistical Analysis System) version 9.2 for Windows was used for the planning of the sample size required to analyze the correlation between the scores of the scales used in the database. The Pearson's correlation coefficient method with Fisher's transformation was applied, with a significance level of $5 \%$, a test power of $80 \%$, and a zero correlation of 0.00 , giving a sample size of at least 46 caregivers. For a null correlation greater than 0.10 , or closer to the minimum correlation of 0.40 , the sample would be 78 caregivers. For a $90 \%$ test power, significance level of $1 \%$ and zero correlation of 0.10 , the suggested sample would be 145 elderly family caregivers, the number reached in the database ${ }^{16}$.

Of the sample of 148 caregivers, $50 \%$ cared for elderly persons with some type of dementia or stroke, $21 \%$ reported that their care recipients were immobile or had a physical disability, and $29 \%$ reported that the elderly had a chronic somatic illness. This information was obtained through an open question that aimed to identify the main medical diagnosis of each elderly care recipient. For the present study, 45 elderly people who cared for other elderly people with dementia and 30 elderly people who cared for elderly people with strokes were chosen from the above-mentioned base sample.

Trained interviewers collected data from the elderly who were recruited from households (62.7\%), at private medical practices $(25.3 \%)$ and in the Geriatric outpatient clinic of a University Hospital $(12 \%)$ in the Greater Campinas Region. The mean duration of the interviews was $57(+13.1)$ minutes.

Data collection took place from October 2014 to July 2015, following approval from the Research Ethics Committee of the Universidade Estadual de Campinas on 6/10/2014 (C.A.A.E. 35868514.8.0000.5404). The subjects confirmed their agreement to participate by signing a Free and Informed Consent Form. The present study complied with Resolution $\mathrm{n}^{\circ}$ 196/96 on the Rights and Regulatory Guidelines on Research Involving Human Beings.
The variables of interest selected for the present study were: the gender, age, burden and perceived quality of life of elderly caregivers, and the type of illness (dementia or stroke) and levels of physical and cognitive dependence of the elderly care recipients.

The Zarit et al. ${ }^{17}$ Burden Interview was used. This consists of 22 items with five points each (from 0 $=$ never to $4=$ always), which assess the caregiver's opinion about how much physical, psychological and social burden is involved in the care they provide ${ }^{9,18}$. The instrument generates a total score ranging from 0 to 88 . The cutoff point for separating the caregivers with the lowest and highest burden is 8 . The higher the score the greater the total perceived burden. In the present study the distribution of the total scores of participants was divided into terciles: 0 to 20 (low burden), 21-28 (moderate burden) and $\geq 29$ (high burden). The three factors described by Bianchi ${ }^{7}$ were also considered: factor 1 (role-related stress) composed of 10 items, factor 2 (intrapsychic stress) with 7 items and 3 factors (presence or absence of competencies and expectations related to care) with 5 items. These factors were identified by means of exploratory factorial analysis achieved following orthogonal varimax rotation and the commonality of the items of the Zarit Burden Interview Scale. ${ }^{7}$

To investigate the quality of life as perceived by the caregiver, the CASP-19 scale was used for individuals aged 55 years and over. This acronym designates control, autonomy, self-realization and pleasure, and is based on Maslow's basic human needs theory ${ }^{19}$. It has 19 items in Likert format (never $=0$, occasionally $=1$, almost always $=2$ and always $=3$ ), with a total score ranging from 0 to $57^{20}$. The scale has undergone semantic-cultural validation and validation of its construct, which is based on a structure composed of two factors, the first of which brings together items from the self-realization and pleasure domains and the second which includes items from the control and autonomy domains generated by confirmatory factorial analyzes ${ }^{20,21}$.

The level of physical impairment of the elderly care recipients was assessed from the Lawton and Brody questionnaire (1969), in a version by Brito, Nunes and Yuaso and by the Katz (1963) scale validated for Brazil by Lino et al. ${ }^{22}$, which investigated the help that each elderly person needed 
to perform Basic Activities of Daily Living (BADL) and Instrumental Activities of Daily Living (IADL). Both have three response options: no help, partial help, or total help. The partial and total help options were included in one possibility - with help. The items of the two scales to which the answer was with help were counted and added together. The distribution was divided into terciles ( 1 to 8, 9 to 12 and 13 activities of daily living impaired).

The level of cognitive impairment of the elderly care recipients was assessed by the Clinical Dementia Rating $-\mathrm{CDR}^{23}$. This instrument assesses the degree of impairment of cognitive functions in people with suspected dementia. It is divided into six categories: memory, orientation, judgment \& problem solving, community affairs, home $\&$ hobbies and personal care. Scores can range from 0 (no dementia) to 3 (severe dementia), with intermediate points 0.5 (uncertain or delayed diagnosis), 1 (mild dementia) and 2 (moderate dementia). The memory domain carries the most weight in the scoring ${ }^{24}$.

The distributions of the caregiver scores on the quality of life and burden scales were submitted to the Kolmogorov-Smirnov test for the evaluation of normality. As the distributions were not normal, non-parametric tests (Chi-square and Fisher's Exact, Mann-Whitney and Kruskal-Wallis) were chosen to compare the two groups of caregivers according to the variables of interest. Fisher's Chi-square and Exact Tests were used to make comparisons between the nominal variables and the Mann-Whitney U-Test was used to compare the ordinal variables. To study the associations between the total score and the two factors of the perceived quality of life scale and the independent variables, univariate logistic regression analysis was performed, followed by multivariate logistic regression analysis. The significance level adopted for the statistical tests was $95 \%$, or $p<0.05$. The data were analyzed using the SAS System for Windows (Statistical Analysis System) software, version 9.2. for Windows ${ }^{25}$.

\section{RESULTS}

Of the 75 caregivers, the majority were female $(81.3 \%)$. The mean age was $69.8(+7)$ years. There were no statistically significant differences between the caregivers of elderly people with dementia and caregivers of the elderly with strokes (Group A and Group B, respectively) in relation to the variables studied (Table 1).

Table 1. Frequencies of gender, age, burden and quality of life of the total sample of caregivers of elderly people with neurological diseases, Campinas, São Paulo, 2016.

\begin{tabular}{|c|c|c|c|c|c|}
\hline & & & Group A* & Group B** & \\
\hline Variable & Condition & $\mathrm{n}$ (total) & $\mathrm{n}(\%)$ & $\mathrm{n}(\%)$ & $\mathrm{p}$-value \\
\hline \multirow[t]{2}{*}{ Gender } & Men & 14 & $10(22.2)$ & $4(13.3)$ & 0.333 \\
\hline & Women & 61 & $35(77.8)$ & $26(86.7)$ & \\
\hline \multirow[t]{3}{*}{ Age } & $60-64$ & 23 & $11(24.5)$ & $12(40.0)$ & 0.339 \\
\hline & 65-69 & 33 & $21(46.7)$ & $12(40.0)$ & \\
\hline & 75 and + & 19 & $13(29.8)$ & $6(20.0)$ & \\
\hline \multirow[t]{3}{*}{ Burden } & $\leq 20$ & 23 & 14 (31.1) & $9(30.0)$ & 0.556 \\
\hline & 21 to 28 & 27 & $18(40.0)$ & $9(30.0)$ & \\
\hline & $\geq 29$ & 25 & $13(29.9)$ & $12(40.0)$ & \\
\hline \multirow[t]{3}{*}{ Role-related stress (Factor 1 of the burden scale) } & $\leq 9$ & 25 & $15(36.6)$ & $10(33.4)$ & 0.056 \\
\hline & 10 to 15 & 23 & $17(33.0)$ & $6(20.0)$ & \\
\hline & $\geq 16$ & 23 & $9(41.0)$ & $14(46.6)$ & \\
\hline \multirow[t]{3}{*}{ Intrapsychic stress (Factor 2 of the burden scale) } & $\leq 1$ & 27 & $17(38.6)$ & $10(33.3)$ & 0.692 \\
\hline & 2 to 4 & 24 & $15(34.2)$ & $9(30.0)$ & \\
\hline & $\geq 5$ & 23 & $12(27.3)$ & $11(36.7)$ & \\
\hline
\end{tabular}


Continuation of Table 1

\begin{tabular}{|c|c|c|c|c|c|}
\hline & & & Group A* & Group B** & \\
\hline Variable & Condition & n (total) & $\mathrm{n}(\%)$ & $\mathrm{n}(\%)$ & p-value \\
\hline \multirow{3}{*}{$\begin{array}{l}\text { Presence or absence of competencies and } \\
\text { expectations related to care. (Factor } 3 \text { of the } \\
\text { burden scale) }\end{array}$} & $\leq 3$ & 27 & $14(34.1)$ & $13(43.3)$ & \multirow[t]{3}{*}{0.642} \\
\hline & 4 a 9 & 22 & $14(34.1)$ & $8(26.6)$ & \\
\hline & $\geq 10$ & 24 & $15(31.8)$ & $9(30.0)$ & \\
\hline \multirow[t]{3}{*}{ Perceived quality of life } & $\leq 38$ & 25 & $15(35.0)$ & $10(33.2)$ & \multirow[t]{3}{*}{0.382} \\
\hline & 39 a 46 & 24 & $12(27.3)$ & $12(40.0)$ & \\
\hline & $\geq 47$ & 26 & $18(40.0)$ & $8(26.8)$ & \\
\hline \multirow{3}{*}{$\begin{array}{l}\text { Sense of self-realization and pleasure } \\
\text { (Factor } 1 \text { of perceived quality of life scale) }\end{array}$} & $\leq 22$ & 27 & $16(37.2)$ & $11(36.6)$ & \multirow[t]{3}{*}{0.375} \\
\hline & 23 a 26 & 21 & $10(23.3)$ & $11(36.6)$ & \\
\hline & $\geq 27$ & 25 & $17(39.5)$ & $8(26.8)$ & \\
\hline \multirow{3}{*}{$\begin{array}{l}\text { Sense of control and autonomy } \\
\text { (Factor } 2 \text { of perceived quality of life scale) }\end{array}$} & $\leq 9$ & 20 & $12(27.2)$ & $8(27.5)$ & \multirow[t]{3}{*}{0.765} \\
\hline & 10 a 12 & 27 & $15(34.0)$ & $12(41.3)$ & \\
\hline & $\geq 13$ & 26 & $17(38.8)$ & $9(31.2)$ & \\
\hline
\end{tabular}

${ }^{*}$ Group $A=$ Caregivers of elderly persons with dementia; ${ }^{*}$ Group $B=$ Caregivers of elderly persons who had suffered a stroke.

The independent variable with the most robust association with low quality of life score was the burden perceived by the caregivers. Caregivers with a higher total score in burden $(\geq 29)$ had a greater chance of low quality of life scores than those with moderate and low burden scores $(\mathrm{OR}=11.43$; $\mathrm{CI}=$ 3.46 - 37.76). Caregivers with high scores for items that represent role-related stress (Factor 1 of the burden scale) had a higher chance of low quality of life scores. Caregivers who scored on the 2 nd tercile of factor 3 of the perceived burden scale (presence or absence of competencies and expectations related to care) were 3.2 times more likely to have low perceived quality of life scores than those who scored in the third tercile and the reference value, according to univariate logistic regression analysis (Table 2).

Higher scores in total burden, role-related stress, intrapsychic stress and the presence or absence of skills and expectations connected to care resulted in greater chances of an outcome of self-realization and pleasure of the elderly caregivers (Factor 1 of CASP-19) (Table 3).

Table 2. Univariate logistic regression analysis for low scores in the quality of life scale of elderly caregivers of other elderly persons with neurological diseases, Campinas, São Paulo, 2016.

\begin{tabular}{lllll}
\hline Variable & Categories & p-value & O.R* & CI 95\% O.R** \\
\hline Gender & Male (ref.)** & --- & 1.00 & --- \\
& Female & 0.283 & 1.81 & $0.61-5.36$ \\
\hline Age & $60-64$ years (ref.) & --- & 1.00 & --- \\
& $65-74$ years & 0.233 & 1.83 & $0.68-4.91$ \\
& $\geq 75$ years & 0.491 & 1.48 & $0.48-4.56$ \\
\hline Diagnosis of Recipient of Care & Dementia (ref.) & --- & 1.00 & --- \\
& Stroke & 0.496 & 1.34 & $0.57-3.15$ \\
\hline Number of partially or totally impaired BADL & $1-8$ (ref.) & --- & 1.00 & --- \\
and IADL**** of care recipients & $9-12$ & 0.570 & 0.69 & $0.19-2.47$ \\
& 13 & 0.903 & 1.06 & $0.42-2.68$ \\
\hline Care recipient score in the measure of & $0-0.5$ (ref.) & --- & 1.00 & --- \\
impairment of cognitive function & $1-2$ & 0.319 & 1.85 & $0.55-6.17$ \\
& 3 & 0.484 & 1.47 & $0.50-4.34$ \\
\hline
\end{tabular}


Continuation of Table 2

\begin{tabular}{|c|c|c|c|c|}
\hline Variable & Categories & $\mathrm{p}$-value & O.R* & CI $95 \%$ O.R** \\
\hline \multirow{3}{*}{ Caregiver score in total perceived burden } & $\leq 20$ (ref.) & --- & 1.00 & --- \\
\hline & $21-28$ & 0.056 & 2.87 & $0.97-8.47$ \\
\hline & $\geq 29$ & $<0.001$ & 11.43 & $3.46-37.76$ \\
\hline \multirow{3}{*}{$\begin{array}{l}\text { Caregiver score in role-related stress } \\
\text { (factor } 1 \text { of burden scale) }\end{array}$} & $\leq 9$ (ref.) & --- & 1.00 & --- \\
\hline & $10-15$ & 0.0100 & 4.33 & $1.43-13.15$ \\
\hline & $\geq 16$ & $<0.001$ & 7.89 & $2.48-25.06$ \\
\hline \multirow{3}{*}{$\begin{array}{l}\text { Caregiver score in intrapsychic stress } \\
\text { (factor } 2 \text { of burden scale) }\end{array}$} & $\leq 1$ (ref.) & -- & 1.00 & --- \\
\hline & $2-4$ & 0.336 & 1.65 & $0.60-4.58$ \\
\hline & $\geq 5$ & 0.090 & 2.46 & $0.87-7.00$ \\
\hline \multirow{3}{*}{$\begin{array}{l}\text { Caregiver score in presence or absence } \\
\text { of competences and expectations related } \\
\text { to care (factor } 3 \text { of burden scale) }\end{array}$} & $\leq 3$ (ref.) & --- & 1.00 & --- \\
\hline & $4-9$ & 0.030 & 3.28 & $1.12-9.58$ \\
\hline & $\geq 10$ & 0.070 & 2.61 & $0.93-7.36$ \\
\hline
\end{tabular}

*Odds Ratio = Relative risk for worse quality of life; $* *$ Confidence interval of $95 \%$ relative risk; ***Reference level; $* * * *$ Basic Activities of Daily Living - BADL and Instrumental Activities of Daily Living - IADL.

Table 3. Univariate logistic regression analysis for low sense of self-realization and pleasure scores in the quality of life of elderly caregivers of other elderly people with neurological diseases. Campinas, São Paulo, 2016.

\begin{tabular}{|c|c|c|c|c|}
\hline Variables & Categories & p-valor & O.R.* & CI95\% O.R.** \\
\hline \multirow[t]{2}{*}{ Gender of caregiver } & Male (ref.)*** & --- & 1.00 & --- \\
\hline & Female & 0.209 & 2.11 & $0.66-6.76$ \\
\hline \multirow[t]{3}{*}{ Age of caregiver } & 60-64 years (ref.) & --- & 1.00 & --- \\
\hline & $65-74$ years & 0.160 & 2.06 & $0.75-5.63$ \\
\hline & $\geq 75$ years & 0.725 & 1.22 & $0.40-3.76$ \\
\hline \multirow[t]{2}{*}{ Diagnosis of Recipient of Care } & Dementia (ref.) & --- & 1.00 & --- \\
\hline & Stroke & 0.555 & 1.30 & $0.55-3.06$ \\
\hline \multirow{3}{*}{$\begin{array}{l}\text { Number of partially or totally impaired BADL } \\
\text { and IADL**** of care recipients }\end{array}$} & $1-8$ (ref.) & --- & 1.00 & --- \\
\hline & $9-12$ & 0.687 & 0.77 & $0.21-2.76$ \\
\hline & 13 & 0.967 & 1.02 & $0.40-2.63$ \\
\hline \multirow{3}{*}{$\begin{array}{l}\text { Care recipient score in the measure of impairment } \\
\text { of cognitive function }\end{array}$} & $0-0.5$ (ref.) & --- & 1.00 & --- \\
\hline & $1-2$ & 0.574 & 1.42 & $0.42-4.82$ \\
\hline & 3 & 0.731 & 1.21 & $0.40-3.67$ \\
\hline \multirow[t]{3}{*}{ Caregiver score in total perceived burden } & $\leq 20$ (ref.) & --- & 1.00 & --- \\
\hline & $21-28$ & 0.052 & 2.97 & $0.99-8.93$ \\
\hline & $\geq 29$ & $<0.001$ & 10.12 & $3.06-33.48$ \\
\hline \multirow{3}{*}{$\begin{array}{l}\text { Caregiver score in role-related stress } \\
\text { (factor } 1 \text { of burden scale) }\end{array}$} & $\leq 9$ (ref.) & --- & 1.00 & --- \\
\hline & $12-15$ & 0.072 & 2.68 & $0.92-7.86$ \\
\hline & $\geq 16$ & 0.003 & 5.35 & $1.74-16.40$ \\
\hline \multirow{3}{*}{$\begin{array}{l}\text { Caregiver score in intrapsychic stress } \\
\text { (factor } 2 \text { of burden scale) }\end{array}$} & $\leq 1$ (ref.) & --- & 1.00 & --- \\
\hline & $2-4$ & 0.638 & 1.28 & $0.46-3.53$ \\
\hline & $\geq 5$ & 0.009 & 4.36 & $1.44-13.18$ \\
\hline \multirow{3}{*}{$\begin{array}{l}\text { Caregiver score in presence or absence of } \\
\text { competences and expectations related to care } \\
\text { (factor } 3 \text { of burden scale) }\end{array}$} & $\leq 3$ (ref.) & --- & 1.00 & --- \\
\hline & $4-9$ & 0.148 & 2.22 & $0.76-6.53$ \\
\hline & $\geq 10$ & 0.019 & 3.59 & $1.23-10.43$ \\
\hline
\end{tabular}

** Odds Ratio = Relative risk for worse quality of life; ${ }^{* *}$ Confidence interval of $95 \%$ relative risk; $* * *$ Reference level; $* * * *$ Basic Activities of Daily Living - BADL and Instrumental Activities of Daily Living - IADL. 
Caregivers with higher total perceived burden scores and those with the highest levels of burden assessed by factor 1 (role-related stress) were 6.93 and
8.45 times more likely, respectively, to have low sense of control and autonomy scores than those that had moderate and low burden scores, as shown in table 4.

Table 4. Univariate logistic regression analysis for low sense of control and autonomy scores in the quality of life of elderly caregivers of other elderly persons with neurological diseases. Campinas, Brazil, 2015-2016.

\begin{tabular}{|c|c|c|c|c|}
\hline Variables & Categories & p-value & O.R.* & CI $95 \%$ O.R** \\
\hline \multirow[t]{2}{*}{ Gender of caregiver } & Male (ref.) ${ }^{* * *}$ & --- & 1.00 & --- \\
\hline & Female & 0.212 & 2.06 & $0.66-6.41$ \\
\hline \multirow[t]{3}{*}{ Age of caregiver } & 60-64 years (ref.) & --- & 1.00 & --- \\
\hline & $65-74$ years & 0.513 & 0.72 & $0.26-1.94$ \\
\hline & $\geq 75$ years & 0.685 & 1.23 & $0.41-3.86$ \\
\hline \multirow[t]{2}{*}{ Diagnosis of Recipient of Care } & Dementia (ref.) & --- & 1.00 & --- \\
\hline & Stroke & 0.663 & 1.21 & $0.51-2.88$ \\
\hline \multirow{3}{*}{$\begin{array}{l}\text { Number of partially or totally impaired } \\
\text { BADL and IADL**** of care recipients }\end{array}$} & $1-8$ (ref.) & --- & 1.00 & --- \\
\hline & $9-12$ & 0.582 & 1.43 & $0.40-5.09$ \\
\hline & 13 & 0.752 & 0.86 & $0.34-2.20$ \\
\hline \multirow{3}{*}{$\begin{array}{l}\text { Care recipient score in the measure of } \\
\text { impairment of cognitive function }\end{array}$} & $0-0.5$ (ref.) & --- & 1.00 & --- \\
\hline & $1-2$ & 0.834 & 1.14 & $0.34-3.76$ \\
\hline & 3 & 0.702 & 0.81 & $0.27-2.40$ \\
\hline \multirow[t]{3}{*}{ Caregiver score in total perceived burden } & $\leq 20$ (ref.) & --- & 1.00 & --- \\
\hline & $21-28$ & 0.173 & 2.12 & $0.72-6.21$ \\
\hline & $\geq 29$ & 0.001 & 6.93 & $2.18-22.01$ \\
\hline \multirow{3}{*}{$\begin{array}{l}\text { Caregiver score in role-related stress } \\
\text { (factor } 1 \text { of burden scale) }\end{array}$} & $\leq 9$ (ref.) & --- & 1.00 & --- \\
\hline & $10-15$ & $<0.001$ & 8.45 & $2.60-27.53$ \\
\hline & $\geq 16$ & $<0.001$ & 8.45 & $2.57-27.84$ \\
\hline \multirow{3}{*}{$\begin{array}{l}\text { Caregiver score in intrapsychic stress } \\
\text { (factor } 2 \text { of burden scale) }\end{array}$} & $\leq 1$ (ref.) & --- & 1.00 & --- \\
\hline & $2-4$ & 0.369 & 1.60 & $0.58-4.44$ \\
\hline & $\geq 5$ & 0.215 & 1.94 & $0.68-5.55$ \\
\hline \multirow{3}{*}{$\begin{array}{l}\text { Caregiver score in presence or absence of } \\
\text { competences and expectations related to care } \\
\text { (factor } 3 \text { of burden scale) }\end{array}$} & $\leq 3$ (ref.) & --- & 1.00 & --- \\
\hline & $4-9$ & 0.246 & 1.87 & $0.65-5.41$ \\
\hline & $\geq 10$ & 0.425 & 1.52 & $0.54-4.27$ \\
\hline
\end{tabular}

** Odds Ratio $=$ Relative risk for worse quality of life; $* *$ Confidence interval of $95 \%$ relative risk; $* * *$ Reference level; $* * * *$ Basic Activities of Daily Living - BADL and Instrumental Activities of Daily Living - IADL.

Four blocks of variables were considered in hierarchical multivariate logistic regression analysis, the dependent variable of which was total quality of life perceived by the caregivers. In block 1 gender and age of caregivers were included; in block 2 , the neurological diseases of the elderly; in block 3 , the levels of physical and cognitive impairment of the elderly care recipients and; in block 4, the measures of perceived burden (total and in each of the three factors).

Based on the results of the hierarchical multivariate analysis, with the Stepwise criterion of variable selection, only the total score of the perceived burden scale was associated with a low total score on the perceived quality of life scale. The 
elderly people with high total burden ( $\geq 29$ points) were 10.8 times more likely to perceive lower levels of quality of life. (CI: $3.16-36.77, p<0.001)$.

\section{DISCUSSION}

The present study characterizes the profile of caregivers of the elderly in terms of gender, age, burden and perceived quality of life, in situations where the caregiver is also elderly. In addition, it describes the characteristics of the care recipients in terms of levels of physical and cognitive dependence and what influences these variables in the perception of quality of life of the elderly caregiver.

The predominance of elderly women in the study sample was similar to the findings of other studies ${ }^{6}$, 26. This corroborates the importance of the role of women in the task of caring, as within the family context women most frequently become caregivers ${ }^{26}$. However, being female did not influence the chance of perceiving a worse quality of life. This finding is in contrast to the study by Lopes and Cachioni ${ }^{6}$ which revealed that women involved in caring perceive more negatives than positives in the act of caring, in comparison with male caregivers.

It was also observed that being elderly is not related to a worse perception of quality of life. Lopes and Cachioni ${ }^{6}$ affirm that the elderly have a more active and participative position in relation to care, a result of the psychologically positive vision that the elderly construct throughout life, which helps them to understand the negative situations of the daily act of caring $^{6}$. There is disagreement among literature on this subject, however. In the study by Guerra et al. ${ }^{27}$ which evaluated caregivers from different age groups, it was found that, in a statistically significant manner, caregivers aged $\geq 50$ years are more likely to perceive a lower quality of life than younger caregivers. The authors justify these results by the conditions of frailty in aging, where the elderly caregivers present functional losses and a decline in their overall health.

The high or low levels of functionality in the elderly affected by the neurological diseases in question, namely strokes and dementia, did not exhibit significant differences in terms of association with perception of quality of life. Bianchi et al. ${ }^{7}$ state that the elderly assume the care of other elderly people despite the psychological discomforts and physical demands of such care as they have an understanding of the difficult circumstances of life and are possibly less psychologically affected by the health situations of the elderly people in question. However, Thober, Creutzberg and Viegas ${ }^{3}$ affirm that high levels of dependence among care recipients can impact the well-being of family caregivers, who generally perform their role without support or adequate guidance, adding to the negative effects on the health of caregivers ${ }^{23}$. Some studies ${ }^{28,29}$ have shown that both strokes and dementia are diseases that negatively affect the quality of life of caregivers.

The data from the present study revealed that the perception of quality of life is strongly associated with caregiver burden. There are multiple factors that contribute to different perceptions of burden and denote poor perceptions of quality of life ${ }^{30,31}$. These include the occupational and financial impact and the loss of support caused by the disease, and difficulties arising from the lack of knowledge on how to deal with the symptoms of the disease. Costa et al. ${ }^{32}$ affirm that changes in the lives of caregivers lead to a strong tendency towards neglecting one's own health, which contributes to the process of burden and, consequently, to a poor quality of life.

The higher levels of intrapsychic stress and expectations related to care demonstrated in this study were strongly associated with a declining perception of quality of life in the domain of self-realization and pleasure. Some studies ${ }^{33}$ have already shown that when there is stress, burden, mental fatigue, there is, therefore, impairment to the perception of quality of life, also explained by the exhausting routine of managing daily activities, which often detract from feelings of pleasure.

On the other hand, intrapsychic stress, which combines feelings of anger, indecision about care and shame, did not have a statistically significant relationship with the perception of a worse quality of life and a worse sense of control and autonomy. According to Paulo and Pires ${ }^{34}$ there is a tendency to neglect or minimize the problems that arise in situations of stress or tension, characteristics of the act of caring. In addition, because they are elderly caregivers, they tend to have a more enjoyable and 
normative view about life. Additionally, a greater sense of personal control leads to more intense feelings of satisfaction, and thus psychic stress affects quality of life less. ${ }^{7}$

The presence or absence of competencies and expectations related to care, that is, the perception that one should be taking better care of the elderly care recipient, had a significant relationship with a worse overall quality of life. Literature ${ }^{9}$ shows that if an elderly care recipient requires support beyond the expectations of the caregiver, it can lead to situations of stress or crisis, a fact that translates into perceptions of a lack of control over life with negative emotions about the quality of life of the caregiver. In addition, even those with a high sense of self-esteem can suffer negative influences from caring and feel sad and lacking in enthusiasm ${ }^{27}$. The perception that one should be doing more or taking better care of someone is constantly related to an expectation of self-efficacy that can circumstantially influence quality of life. ${ }^{12}$ The difficulties experienced by caring for a highly dependent elderly person usually lead caregivers to relinquish their social relationships, resulting in negative effects on their sense of personal realization ${ }^{27}$.

One limitation of the present study is the relatively small sample size which may have contributed to the statistical inferences. The data refer only to caregivers of patients with dementia or a stroke. Caring for the elderly with other diseases such as Parkinson's or multiple sclerosis may reveal different perceptions on the quality of life of the elderly caregiver. Furthermore, because it is a cross-sectional study, no conclusions can be drawn about causality. A longitudinal study may provide more accurate information about the situations that influence the quality of life of the elderly caregiver. Despite this, the data presented represent a step forward in understanding issues that encompass care in the lives of elderly caregivers.

\section{REFERENCES}

1. Rocha-Brischiliari SC, Agnolo CMD, Gravena AAF, Lopes TCR, Carvalho MDB, Pelloso SM. Doenças crônicas não transmissíveis e associação com fatores de risco. Rev Bras Cardiol. 2014;27(1):35-42.

\section{CONCLUSION}

The data revealed by the present study demonstrate that the perception of quality of life of elderly people who care for other elderly people with neurological diseases (dementia and strokes) is not negatively influenced by gender, age, diagnosis, and the functional dependence or cognitive status of the elderly care recipient, despite the critical events of aging. However, these same data reveal that perceived burden negatively influences the quality of life of the caregiver. This indicates the importance of increasing our knowledge of the circumstances that cause burden among elderly caregivers, so that the awareness of such individuals about the emotional situations they are experiencing can be raised and they can seek help in the appropriate health services.

In contributions to the field of study it is important to highlight that the present study contemplates a better understanding of the perception of quality of life of elderly caregivers, as a large part of related studies involve young individuals. Identifying the emotional and instrumental needs of elderly people that care for other elderly individuals is essential, as due to population aging this group is increasingly present in Brazil and throughout the world. Therefore, developing and applying new strategies of support and physical and psychological assistance for the elderly and primarily those who suffer from a daily burden of care is an emerging Geriatric and Gerontological practice.

It is therefore important to encourage health professionals to consciously reflect upon the difficulties that elderly caregivers face in their daily lives. Experience and knowledge about elderly caregivers is crucial to a proactive attitude towards the various difficulties experienced by this population segment. It is important that health professionals improve their recognition of elderly caregivers who feel emotionally and physically burdened.

2. Silva BM, Carreira L, Marcon SS. Envelhecimento populacional e doenças crônicas: reflexões sobre os desafios para o Sistema de Saúde Pública. Rev Kairós. 2015;18(1):325-39. 
3. Guerra ZF, de Morais EC, Vieira Júnior PRM, Soares PA. Avaliação da capacidade funcional pós acidente vascular cerebral (AVC). Rev Bras Ciênc Med Saúde. 2017;5(5):1-5.

4. D'Onofrio G, Sancarlo D, Addante F, Ciccone F, Cascavilla L, Paris F, et al. Caregiver burden characterization in patients with Alzheimer's disease or vascular dementia. Int J Geriatr Psychiat. 2015;30(9):891-9.

5. Santos NMF, Tavares DMS. Correlação entre qualidade de vida e morbidade do cuidador de idoso com acidente vascular encefálico. Rev Esc Enferm USP. 2012;46:960-6.

6. Lopes LO, Cachioni M. Cuidadores familiares de idosos com doença de Alzheimer em uma intervenção psicoeducacional. Rev Bras Geriatr Gerontol. 2013;16(3):443-60.

7. Bianchi M, Flesch LD, Alves EVC, Batistoni SST, Neri AL. Zarit burden interview psychometric indicators applied in older people caregivers of other elderly. Rev Latinoam Enferm. 2016;24:1-12.

8. Gonçalves LTH, Leite MT, Hildebrandt LM, Bisogno SC, Biasuz S, Falcade BL. Convívio e cuidado familiar na quarta idade: qualidade de vida de idosos e seus cuidadores. Rev Bras Geriatr Gerontol. 2013;16(2):315-25.

9. Fuhrmann AC, Bierhals CCBK, dos Santos NO, Paskulin LMG. Association between the functional capacity of dependant elderly people and the burden of family caregivers. Rev Gaúcha Enferm. 2015;36(1):14-20.

10. Christofoletti G, Carregaro RL, Oliani MM, Stella F, Bucken-Gobbi LT, Gobbi S. Locomoção, distúrbios neuropsiquiátricos e alterações do sono de pacientes com demência e seus cuidadores. Fisioter Mov. 2013;26(1):47-53.

11. Loureiro LSN, Fernandes MGM, da Nóbrega MML, Rodrigues RAP. Sobrecarga em cuidadores familiares de idosos: associação com características do idoso e demanda de cuidado. Rev Bras Enferm. 2014;67(2):227-32.

12. Caldeira RB, Neri AL, Batistoni SST, Cachioni M. Variáveis associadas à satisfação com a vida em cuidadores idosos de parentes também idosos cronicamente doentes e dependentes. Rev Bras Geriatr Gerontol. 2017; 20(4):502-15.

13. Wachholz PA, Santos RCC, Wolf LSP. Reconhecendo a sobrecarga e a qualidade de vida de cuidadores familiares de idosos frágeis. Rev Bras Geriatr Gerontol. 2013;16(3):513-26.

14. Reis LA, Santos KT, Reis LA, Gomes NP. Quality of life and associated factors for caregivers of functionally impaired elderly people. Braz J PhysTher. 2013;17(2):146-51
15. Damasceno A, Delicio AM, Mazo DFC, Zullo JFD, Scherer P, Ng RTY, et al. Validation of the Brazilian version of mini-test CASI-S. Arq Neuropsiquiatr. 2005;63(2b):416-21.

16. Fleiss JL. Statistical Methods for Rates and Proportions. New York: John Wiley \& Sons; 1981.

17. Boyacıoğlu NE, Yasemin K. The Effectiveness of psychoeducational interventions in reducing the care burden of family members caring for the elderly in Turkey: a randomized controlled study. Arch Psychiatr Nurs. 2017;31:183-9.

18. Ferreira F, Pinto A, Laranjeira A, Pinto AC, Lopes A, Viana A, et al. Validação da escala de Zarit: sobrecarga do cuidador em cuidados paliativos domiciliários, para população portuguesa. Rev Cad Saúde. 2010;3(2):13-9.

19. Maslow AH. Toward a psychology of being. 2nd ed. Princeton: Van Nostrand; 1968.

20. Hyde M, Wiggins RD, Higgs P, Blane DB. A Measure of quality of life in early old age: the theory, development and properties of a needs satisfaction model (CASP-19). Aging Ment Health. 2003;7(3):186-94.

21. Flesch LD, Batistonia SST, Neri AL, Cachioni M. Aspectos psicológicos da qualidade de vida de cuidadores de idosos: uma revisão integrativa. Geriatr Gerontol Aging. 2017;11(3):138-49.

22. Santos-Orlandi AA, Brito TRP, Ottaviani AC, Rossetti ES, Zazzetta MS, Gratão ACM, et al . Perfil de idosos que cuidam de outros idosos em contexto de alta vulnerabilidade social. Esc Anna Nery. 2017;21(1):1-8.

23. Liu J, Wang LN, Tan JP, Ji P, Gauthier S, Zhang Yl, et al. Burden, anxiety and depression in caregivers of veterans with dementia in Beijing. Arch Gerontol Geriatr. 2012;55(3):560-3.

24. Morris JC. The Clinical Dementia Rating (CDR): current version and scoring rules. Neurology. 1993;43(11):1983-4.

25. Lawson AB. Statistical Methods in Spatial Epidemiology. 2nd . John Wiley \& Sons; 2006. Software. p.363-6.

26. Neri AL, Yassuda MS, Fortes-Burgos ACG, Mantovani EP, Arbex FS, de Souza Torres SV, et al. Relationships between gender, age, family conditions, physical and mental health, and social isolation of elderly caregivers. Int Psychogeriatr. 2012;24(3):472-83.

27. Guerra HS, Almeida NAM, Souza MR, Minamisava R, Tobias GC. Qualidade de vida dos cuidadores de um serviço de atenção domiciliar. Rev enferm UFPE. 2017;11(Supl. 1):254-63.

28. de Lima ML, Santos JLF, Sawada NO, de Lima LAP. Quality of life of individuals with stroke and their caregivers in a city of Triângulo Mineiro. Rev Bras Epidemiol. 2014;17:453-64. 
29. Inouye K, Pedrazzani ES, Pavarini SCI. Implicações da doença de Alzheimer na qualidade de vida do cuidador: um estudo comparativo. Cad Saúde Pública. 2010;26(5):891-9.

30. Santos-García D, de la Fuente-Fernández R. Factors contributing to caregivers' stress and burden in Parkinson's disease. Acta Neurol Scand. 2015;131(4):203-10.

31. Srivastava G, Tripathi RK, Tiwari SC, Singh B, Tripathi SM. Caregiver burden and quality of life of key caregivers of patients with dementia. Indian J Psychol Med. 2016;38(2):133-6.
32. da Costa TF, Costa KNFM, Fernandes MGM, Martins KP, Brito SS. Quality of life of caregivers for patients of cerebrovascular accidents: association of (socio-demographic) characteristics and burden. Rev Esc Enferm USP. 2015;49(2):245-52.

33. de Souza LR, Hanus JS, Dela Libera LB, Silva VM, Mangilli EM, Simões PW, et al. Sobrecarga no cuidado, estresse e impacto na qualidade de vida de cuidadores domiciliares assistidos na atenção básica. Cad Saúde Colet. 2015;23(2):140-9.

34. Paulo AMR, Pires AP. Operacionalização psicodinâmica de diagnóstico (OPD-2) numa psicanálise. Psicol Clín. 2013;25(1):163-78. 